\title{
Effect of nitrogen addition to ozone generation characteristics by diffuse and filamentary dielectric barrier discharges at atmospheric pressure ${ }^{\star}$
}

\author{
Naoki Osawa ${ }^{a}$, Takafumi Tsuji, Ryota Ogiso, and Yoshio Yoshioka \\ Kanazawa Institute of Technology, 7-1 Ohgigaoka Nonoichi Ishikawa, Japan
}

Received: 14 December 2016 / Received in final form: 28 February 2017 / Accepted: 13 April 2017 (c) The Author(s) 2017

\begin{abstract}
Ozone is widely used for gas treatment, advanced oxidation processes, microorganisms inactivation, etc. In this research, we investigated the effect of nitrogen addition to ozone generation characteristics by atmospheric pressure Townsend discharge (APTD) type and filamentary dielectric barrier discharge (DBD) type ozone generators. The result showed that the ozone generated by the filamentary DBD increases rapidly with the increase of $\mathrm{O}_{2}$ content, and is higher than that by the APTD. On the other hand, it is interesting that the ozone generated by the APTD gradually decreases with the increase of $\mathrm{O}_{2}$ content. In order to clarify why the characteristics of ozone generation by the two kinds of discharge modes showed different dependency to the $\mathrm{N}_{2}$ content, we analyzed the exhaust gas composition using FTIR spectroscopy and calculated the rate coefficients using BOLSIG+ code. As a result, we found that although $\mathrm{O}_{2}$ content decreased with increasing $\mathrm{N}_{2}$ content, additional $\mathrm{O}$ atoms produced by excited $\mathrm{N}_{2}$ molecules contribute to ozone generation in case of APTD.
\end{abstract}

\section{Introduction}

Dielectric Barrier Discharge (DBD) type ozone generators are widely used for gas treatment [1], Advanced Oxidation Processes (AOPs) for treatment of water [2], microorganisms inactivation [3], etc. So far, various methods have been studied to improve the energy efficiency [4] and the ozone yield [5]. We have investigated efficient ozone generating methods by DBD. One of the investigations was a numerical simulation of chemical reactions [6]. The results showed that since the $\mathrm{O}$ radicals are generated mainly at the center of filamentary micro discharges (FDs), the ozone generation efficiency is governed by the diffusion speed of $\mathrm{O}$ radicals. Therefore, we considered that diffuse DBD will improve the ozone yield, because the $\mathrm{O}$ radicals are generated in the whole discharge space. After the study, we succeeded in generating a diffuse DBD in air, $\mathrm{N}_{2}$ and $\mathrm{O}_{2}$ at atmospheric pressure by a DBD device using alumina barriers [7]. The DBD was found to be a kind of atmospheric pressure Townsend discharge (APTD). Then, we applied the APTD to air-fed and $\mathrm{O}_{2}$-fed ozone generators, and investigated the ozone yield $[8,9]$. As a result, we found that (1) in the case of air-fed ozone generator,

\footnotetext{
${ }^{a}$ e-mail: n.osawa@neptune.kanazawa-it.ac.jp

${ }^{\star}$ Contribution to the topical issue "The 15th International Symposium on High Pressure Low Temperature Plasma Chemistry (HAKONE XV)", edited by Nicolas Gherardi and Tomáš Hoder
}

the ozone yield by the APTD was lower than that by the filamentary DBD in the small specific input energy (SIE) region. However in the large SIE region, the yield by the APTD was higher than that by the filamentary DBD, (2) in the case of $\mathrm{O}_{2}$-fed ozone generator, the maximum ozone yield by APTD was almost the same as that obtained by air-fed ozone generators. We also investigated the by-products generation characteristics by the two kinds of air-fed ozone generators using FTIR spectroscopy [10]. As a result, it was found that concentrations of $\mathrm{HNO}_{3}, \mathrm{~N}_{2} \mathrm{O}_{5}$ and $\mathrm{N}_{2} \mathrm{O}$ in ozone gas by APTD type ozone generators were lower than those of by filamentary DBD type ozone generators at the same ozone concentration. It was understood that the lower reduced electric field of APTD suppressed the formation of the nitrogen oxides $[10,11]$.

In the case of filamentary DBD type air-fed ozone generators, the ozone generation mechanisms were clarified by numerical simulations of plasma chemical kinetics and experiments. The existence of nitrogen molecules lead to (1) ozone decomposition by the catalytic reactions of $\mathrm{NO}$ and $\mathrm{NO}_{2}[12],(2)$ but on the other hand, there is an additional ozone formation by subsequent nitrogen atoms [1]. Since the effect of ozone decomposition reactions are bigger than that of additional ozone formation reactions by nitrogen atoms, the ozone yields by air-fed ozone generators are low in comparison with $\mathrm{O}_{2}$-fed ozone generators. However, in the case of APTD type ozone generators, the maximum ozone yield of the $\mathrm{O}_{2}$-fed ozone generator 


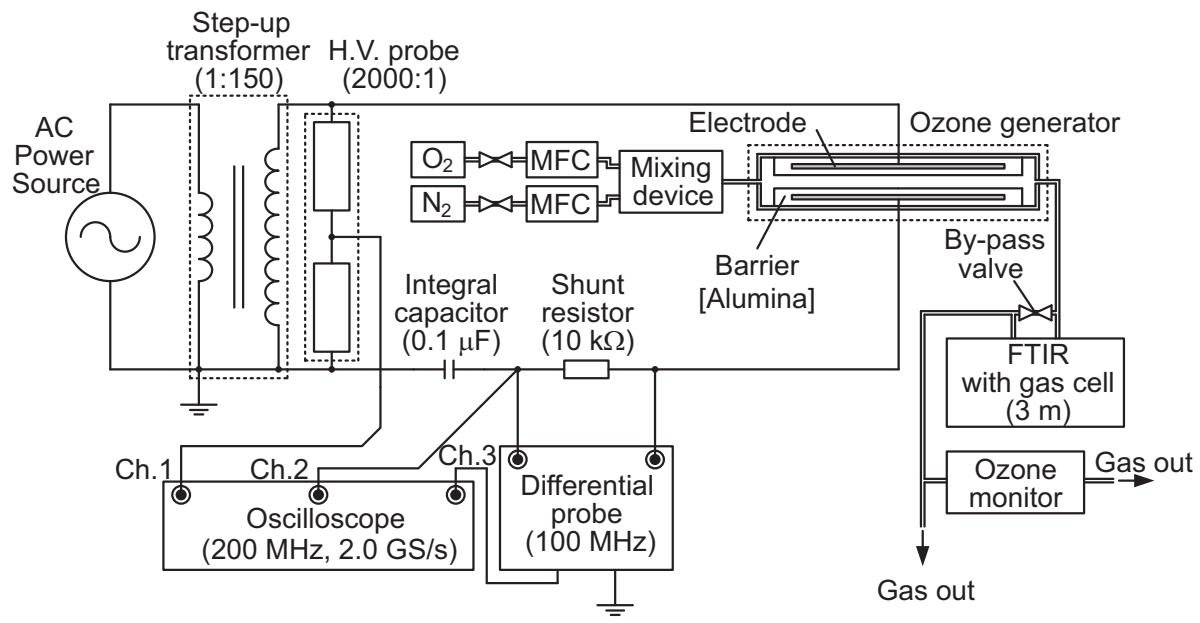

Fig. 1. Experimental setup.

was almost the same as that obtained by air-fed ozone generators. Therefore, it seems that the ozone generation mechanism is different from filamentary DBD ozone generators.

In this paper, in order to clarify why the ozone yield by APTD did not increase by using $\mathrm{O}_{2}$ as source gas, we investigated the effect of the admixture ratio of $\mathrm{N}_{2}$ and $\mathrm{O}_{2}$ in source gas.

\section{Experimental setup}

Figure 1 shows an experimental setup. $\mathrm{O}_{2}$ (purity: 99.5\%) and $\mathrm{N}_{2}$ (purity: 99.95\%) were used as source gas of the ozone generator [13]. Absolute humidity of these gases was $119.3 \mathrm{mg} / \mathrm{m}^{3}$. Total flow rate of the mixed gas was fixed to $2.0 \mathrm{~L} / \mathrm{min}$ using two mass flow controllers (SEC$400 \mathrm{mk} 3$, Horiba Ltd.). The admixture ratio of $\mathrm{N}_{2}$ and $\mathrm{O}_{2}$ was changed by changing flow rates of $\mathrm{N}_{2}$ and $\mathrm{O}_{2}$ gases. Ozone concentration was measured by an UV absorption type ozone monitor (EG-3000B/01, Ebara Jitsugyo Co., Ltd.). Nitrogen oxides were analyzed by FTIR spectroscopy (IR Affinity-1, Shimadzu Co.) with a gas cell (optical path length: $3 \mathrm{~m}$, Gemini Scientific Instruments). $\mathrm{AC}$ high voltage was applied to the ozone generator by a step-up transformer. The maximum applied voltage $(V)$ and frequency were $13.6 \mathrm{kVp}$ and $50 \mathrm{~Hz}$ respectively. The applied voltage and the current were measured by an oscilloscope (TDS-2024B, Tektronix, Inc.) using a high voltage probe (EP-50K, Pulse Electronic Engineering Co., Ltd.) and a differential probe (700924, Yokogawa Electric Co.) respectively. The integral of the current (charge $q$ ) was measured from the voltage drop across an integral capacitor $(0.1 \mu \mathrm{F})$. Besides, the discharge power was calculated by multiplying the area of $V-q$ Lissajous figure by power frequency. Alumina (Material code: A473 and A440, thickness: $1 \mathrm{~mm}$, Kyocera Co.) was used as the barrier material of the discharge device. Here, A473 alumina barrier can generate APTD, on the other hand, A440 alumna barrier cannot generate APTD. Relative permittivity and surface roughness of barriers are almost the same [10].
The electrode size was $62 \mathrm{~cm}^{2}$. We used the plane type ozone generators $[8,9]$. The gap length was fixed to $2 \mathrm{~mm}$.

\section{Results}

\subsection{Discharge characteristics of APTD and filamentary DBD}

Figure 2 shows discharge characteristics of the DBD device using A473 alumina. The admixture ratio of $\mathrm{N}_{2} / \mathrm{O}_{2}$ was changed in this experiment [13]. From Figure 2a, it is seen that the discharge current flowed continuously without sharp pulses at all admixture ratios. Looking at the figure more precisely, it can be seen that the inception of the discharges became faster with the increase of $\mathrm{O}_{2}$ content. Gap voltage during discharge can be calculated from the difference of voltages applied to the DBD device and to the barrier plates [14]. The gap voltages thus calculated are also shown in Figure 2a. It is seen that the gap voltages are constant during discharge at all admixture ratios, however the values became smaller with increasing the $\mathrm{O}_{2}$ content. It is because the electric fields required for Townsend breakdown of $\mathrm{O}_{2}$ gas is lower than that of $\mathrm{N}_{2}$ gas [15]. From Figure 2a, it is apparent that APTDs were generated not only in $100 \% \mathrm{~N}_{2}$ but also in any $\mathrm{N}_{2} / \mathrm{O}_{2}$ mixed gas. In the literature $[16,17]$, it is described that the APTD in pure nitrogen can be maintained by seed electrons created by collisions between $\mathrm{N}_{2}\left(\mathrm{~A}^{3} \Sigma_{u}^{+}\right)$and $\mathrm{N}_{2}\left(\mathrm{a}^{1} \Sigma_{u}^{-}\right)$. If a small amount of $\mathrm{O}_{2}$ is mixed in $\mathrm{N}_{2}$ gas, these metastable are quenched, and the discharge mode changes from APTD to filamentary DBD. However, since our APTD can be generated in all gas conditions, we had to consider another mechanism. We think that homogeneity of the charged particles (electrons and/or ions) deposition, desorption and secondary electron emission from alumina barrier are playing an important role to the generation of our APTD $[10,11]$. Figure $2 \mathrm{~b}$ shows $V$ - $q$ Lissajous figures. All $\mathrm{N}_{2} / \mathrm{O}_{2}$ mixtures show a parallelogram. Discharge sustaining voltage $\left(V_{g}\right)$ increased with increasing $\mathrm{N}_{2}$ content. On the other hand, the amount of 
(a)

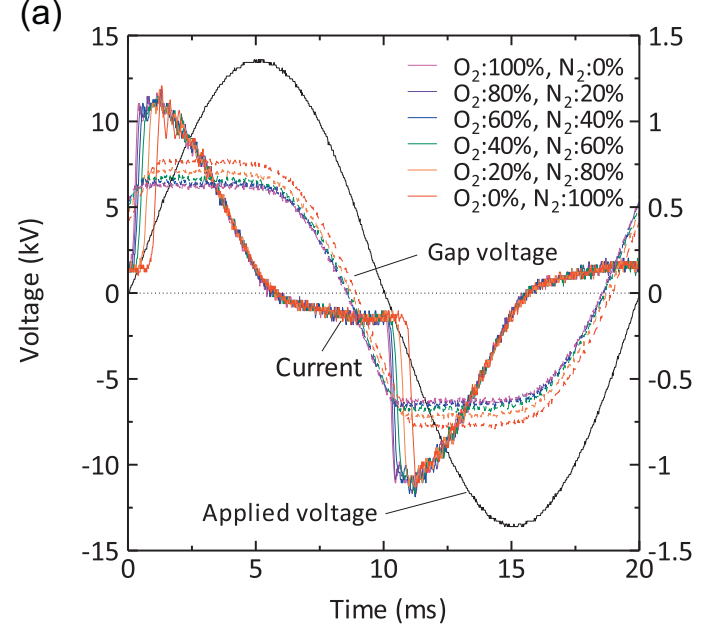

(c)

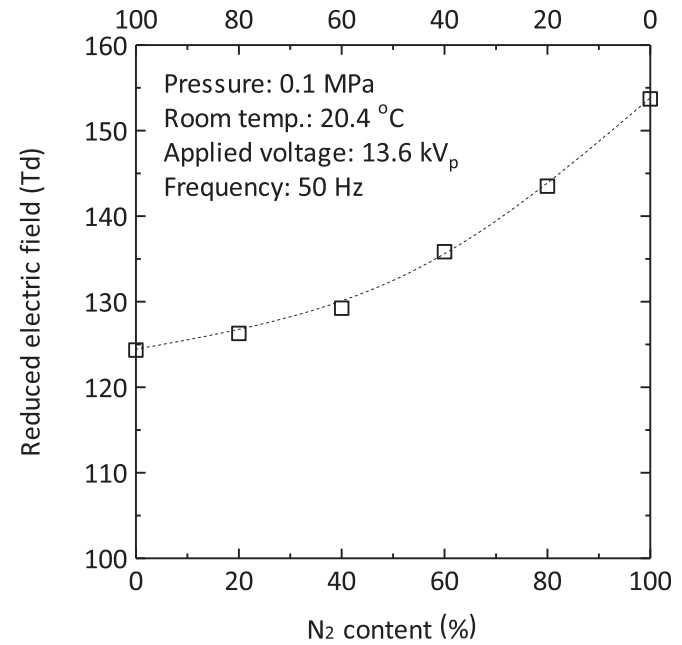

(b)

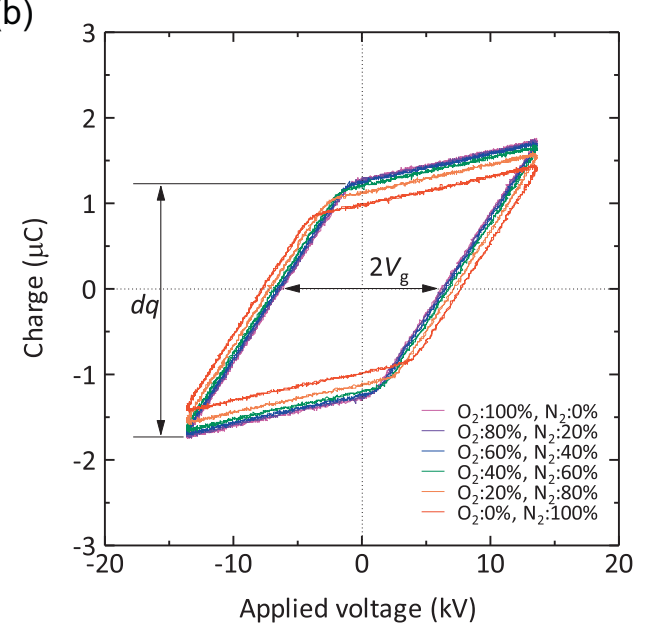

(d)

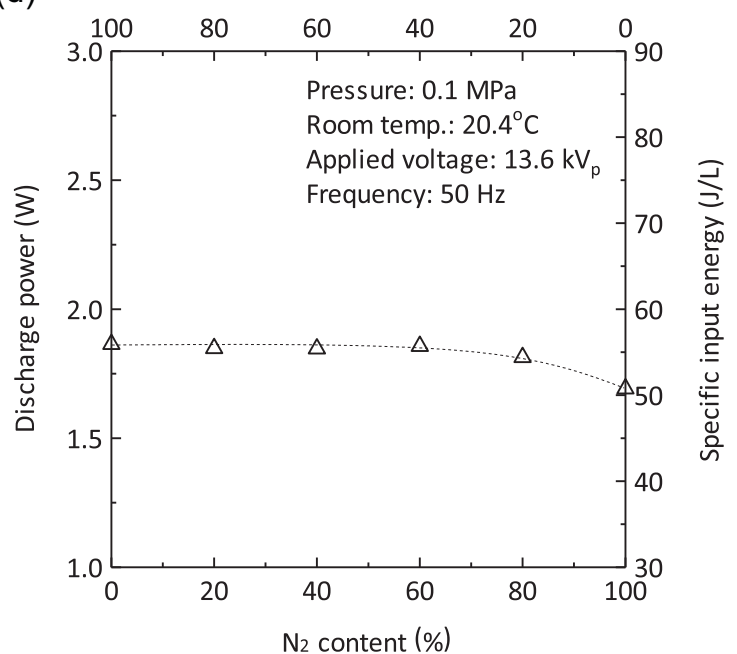

Fig. 2. Discharge characteristics of APTD. (a) Voltage and current waveforms, (b) Lissajous figures, (c) reduced electric field and (d) discharge power and SIE at various $\mathrm{N}_{2}$ content.

charge during discharge $(d q)$ decreased with increasing $\mathrm{N}_{2}$ content. Figure 2c shows the reduced electric field $(E / n)$ calculated by dividing the electric field strength between barriers during discharge $\left(=V_{g} / d\right)$ by gas density [11]. Since $V_{g}$ increased with increasing $\mathrm{N}_{2}$ content, $E / n$ increased with increasing $\mathrm{N}_{2}$ content. Figure $2 \mathrm{~d}$ shows the change of the discharge power and the SIE as a function of $\mathrm{N}_{2}$ content. Although the applied voltages were all the same, the discharge power at $100 \% \mathrm{~N}_{2}$ became smaller in comparison with the other cases.

Figure 3 shows discharge characteristics of the DBD device using A440 alumina by different admixture ratio of $\mathrm{N}_{2} / \mathrm{O}_{2}$. Figures $3 \mathrm{a}$ and $3 \mathrm{~b}$ show the current and gap voltage waveforms at the conditions of $100 \% \mathrm{~N}_{2}$ and $100 \% \mathrm{O}_{2}$. The discharge currents contained many pulses. They are due to the generation of filamentary DBD. Figure 3c shows $V-q$ Lissajous figures of the discharges at various admixture ratios of $\mathrm{N}_{2}$ and $\mathrm{O}_{2}$. Contrary to the case of APTD, the parallelograms at different $\mathrm{N}_{2} / \mathrm{O}_{2}$ admixture ratio are almost identical. Figure $3 \mathrm{~d}$ shows the change of the discharge power and the SIE as a function of $\mathrm{N}_{2}$ content. They are around $2.2 \mathrm{~W}$ and there is no change by the admixture ratio.

\subsection{Ozone generation characteristics}

Figure 4 shows the ozone concentration at various $\mathrm{N}_{2}$ contents generated by the discharges with the two kinds of discharge modes. As it is seen in the figure, the ozone generated by the filamentary DBD increases rapidly with the increase of $\mathrm{O}_{2}$ content, and is higher than that by the APTD. On the other hand, it is interesting that ozone generated by the APTD gradually decreases with the increase of $\mathrm{O}_{2}$ content. Since the $E / n$ at the streamer head of filamentary DBD is higher than the $E / n$ of the APTD $[11,18]$, the high $E / n$ is effective to the $\mathrm{O}_{2}$ dissociation reaction and the subsequent ozone generation reaction becomes active.

Figure 5 shows the ozone yield at various $\mathrm{N}_{2}$ contents by two kinds of discharge modes. In the case of filamentary $\mathrm{DBD}$, the ozone yield of was $185 \mathrm{~g} / \mathrm{kWh}$ for $100 \% \mathrm{O}_{2}$. 
(a)

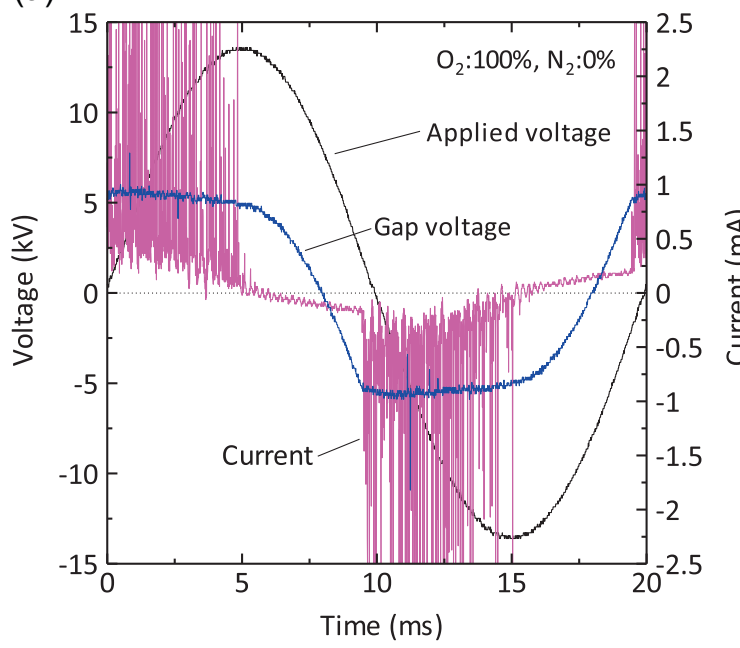

(c)

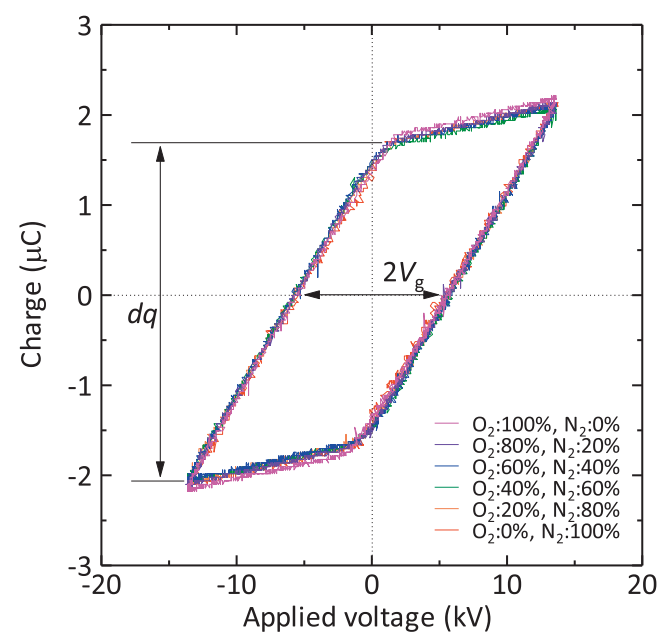

(b)

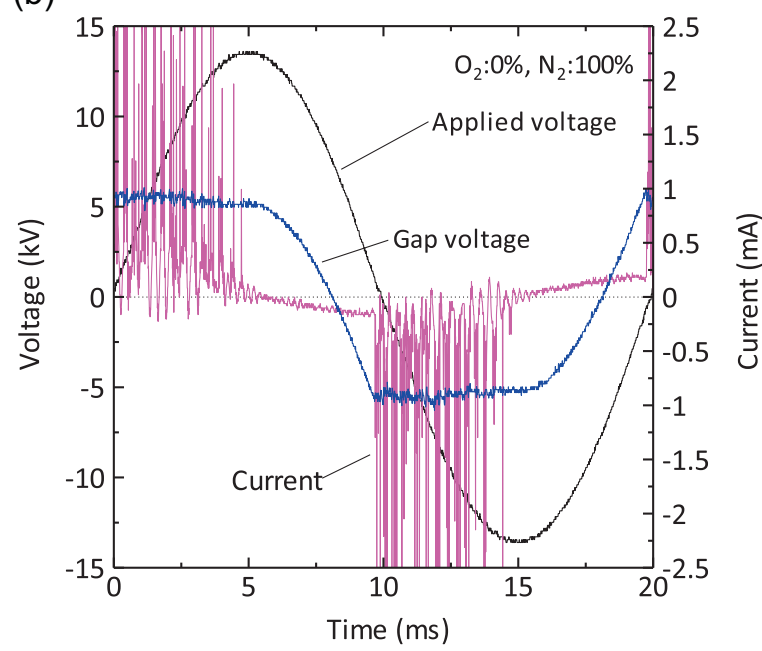

(d)

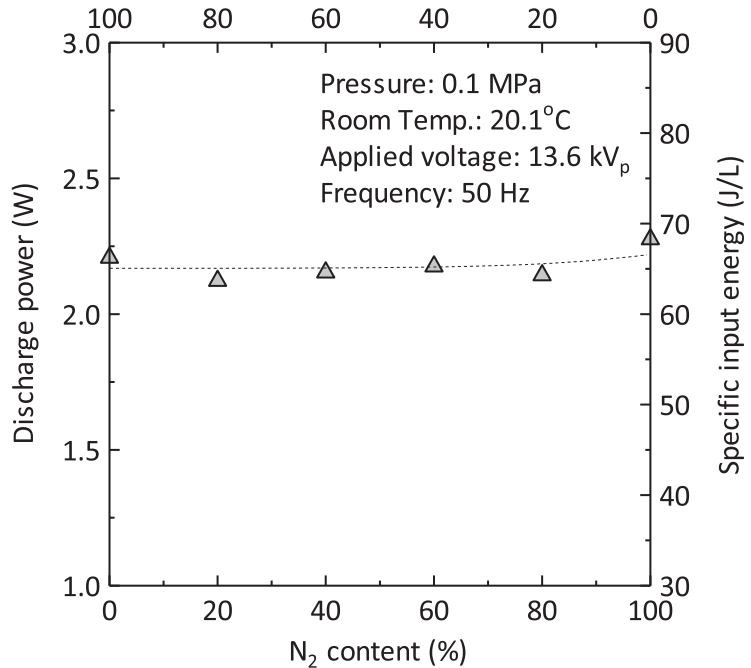

Fig. 3. Discharge characteristics of filamentary DBD. (a) Voltage and current waveforms $\left(\mathrm{N}_{2} / \mathrm{O}_{2}: 0 \% / 100 \%\right)$, (b) voltage and current waveforms $\left(\mathrm{N}_{2} / \mathrm{O}_{2}: 100 \% / 0 \%\right)$, (c) Lissajous figures and (d) discharge power and SIE at various $\mathrm{N}_{2}$ content.

In the case of APTD, ozone yield was $26 \mathrm{~g} / \mathrm{kWh}$ for $100 \%$ $\mathrm{O}_{2}$. At the same $\mathrm{N}_{2}$ content, ozone yield by filamentary DBD was higher than that of by APTD.

\section{Discussions}

In order to clarify why the characteristics of ozone generation by the two kinds of discharge modes showed different dependency to the $\mathrm{N}_{2}$ content, we investigated the absorbance spectra of $320 \mathrm{ppm}$ ozone gas generated by filamentary DBD and APTD using FTIR spectroscopy. In this experiment, in order to use the ozone with the same concentration by filamentary DBD and by APTD, applied voltage and frequency were adjusted as shown in Table 1.

Figure 6 shows the absorbance spectra of $320 \mathrm{ppm}$ ozone gas generated by the two kinds of DBD. In the ozone generated by the filamentary $\mathrm{DBD}$, besides ozone, $\mathrm{HNO}_{3}$,
$\mathrm{N}_{2} \mathrm{O}, \mathrm{NO}_{2}$ and $\mathrm{N}_{2} \mathrm{O}_{5}$ were detected as by-products. On the other hand, in the ozone generated by the APTD, $\mathrm{HNO}_{3}, \mathrm{~N}_{2} \mathrm{O}$ and $\mathrm{N}_{2} \mathrm{O}_{5}$ were detected as by-products. As it is seen in the figure, the intensities of the absorbance spectra of $\mathrm{O}_{3}$ and $\mathrm{N}_{2} \mathrm{O}$ by the filamentary DBD and by the APTD were almost the same, however the intensities of the absorbance spectra of $\mathrm{HNO}_{3}, \mathrm{NO}_{2}$ and $\mathrm{N}_{2} \mathrm{O}_{5}$ by the APTD were lower than those by the filamentary DBD.

In general, dissociation of $\mathrm{O}_{2}$ and $\mathrm{N}_{2}$ by electron impact (R1)-(R3) and subsequent NOx formation (R4)-(R8) occur by the following reactions $[18,19]$ :

$$
\text { see reactions }(\mathrm{R} 1)-(\mathrm{R} 8) \text { in the next page. }
$$

Because the $E / n$ of APTD is lower than that of streamer head of filamentary DBD $[11,18], \mathrm{N}_{2}$ dissociation reaction $(\mathrm{R} 1)$ by $\mathrm{APTD}$ is weak and therefore the subsequent NOx formation (R4)-(R8) are small. Namely, the intensities of absorbance spectra of $\mathrm{NO}_{2}$ and $\mathrm{N}_{2} \mathrm{O}_{5}$ 


$$
\begin{array}{ll}
\mathrm{N}_{2} \text { dissociation: } & \mathrm{e}+\mathrm{N}_{2} \rightarrow \mathrm{N}_{2}{ }^{*}+\mathrm{e} \rightarrow 2 \mathrm{~N}+\mathrm{e}(13 \mathrm{eV}) \\
\mathrm{O}_{2} \text { dissociation: } & \mathrm{e}+\mathrm{O}_{2} \rightarrow \mathrm{O}_{2}\left(\mathrm{~A}^{3} \Sigma_{\mathrm{u}}^{+}\right)+\mathrm{e} \rightarrow \mathrm{O}\left({ }^{3} \mathrm{P}\right)+\mathrm{O}\left({ }^{3} \mathrm{P}\right)+\mathrm{e}(6.1 \mathrm{eV}) \\
\mathrm{O}_{2} \text { dissociation: } & \mathrm{e}+\mathrm{O}_{2} \rightarrow \mathrm{O}_{2}\left(\mathrm{~B}^{3} \Sigma_{\mathrm{u}}^{-}\right)+\mathrm{e} \rightarrow \mathrm{O}\left({ }^{3} \mathrm{P}\right)+\mathrm{O}\left({ }^{1} \mathrm{D}\right)+\mathrm{e}(8.4 \mathrm{eV}) \\
\mathrm{NO} \text { generation: } & \mathrm{N}+\mathrm{O}_{2} \rightarrow \mathrm{NO}+\mathrm{O} \\
\mathrm{NO}_{2} \text { formation: } & \mathrm{O}+\mathrm{NO}+\mathrm{M} \rightarrow \mathrm{NO}_{2}+\mathrm{M} \\
& \mathrm{NO}+\mathrm{O}_{3} \rightarrow \mathrm{NO}_{2}+\mathrm{O}_{2} \\
\mathrm{NO}_{3} \text { formation: } & \mathrm{NO}_{2}+\mathrm{O}_{3} \rightarrow \mathrm{NO}_{3}+\mathrm{O}_{2} \\
\mathrm{~N}_{2} \mathrm{O}_{5} \text { formation: } & \mathrm{NO}_{2}+\mathrm{NO}_{3}+\mathrm{M} \rightarrow \mathrm{N}_{2} \mathrm{O}_{5}+\mathrm{M}
\end{array}
$$

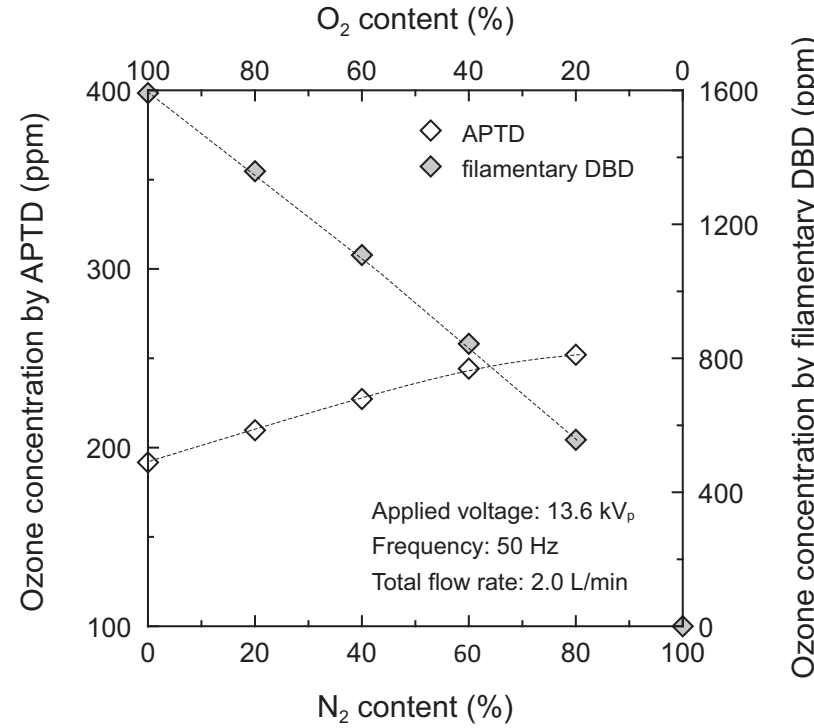

Fig. 4. Ozone concentration by the two kinds of discharge modes as a function of $\mathrm{N}_{2}$ content.

by the APTD type ozone generator were lower than that of by filamentary DBD type ozone generator. On the other hand, the intensities of the absorbance spectrum of $\mathrm{N}_{2} \mathrm{O}$ by the filamentary DBD and by APTD are almost the same. These results suggest that, in APTD, $\mathrm{N}_{2}$ excitation reactions (R9) and (R10) seem to be dominant in comparison with $\mathrm{N}_{2}$ dissociation (R1). For that reason, excited $\mathrm{N}_{2}$ molecules can produce $\mathrm{N}_{2} \mathrm{O}(\mathrm{R} 11)$.

$\mathrm{N}_{2}$ excitation:

$$
\begin{aligned}
& \mathrm{e}+\mathrm{N}_{2} \rightarrow \mathrm{N}_{2}\left(\mathrm{~A}^{3} \Sigma_{\mathrm{u}}^{+}\right)+\mathrm{e}(6.17 \mathrm{eV}) \\
& \mathrm{e}+\mathrm{N}_{2} \rightarrow \mathrm{N}_{2}\left(\mathrm{~B}^{3} \Pi_{\mathrm{g}}\right)+\mathrm{e}(7.35 \mathrm{eV})
\end{aligned}
$$

$\mathrm{N}_{2} \mathrm{O}$ generation:

$$
\mathrm{N}_{2}(\mathrm{~A})+\mathrm{O}_{2} \rightarrow \mathrm{N}_{2} \mathrm{O}+\mathrm{O}
$$

On the other hand, these excited $\mathrm{N}_{2}$ molecules can produce additional $\mathrm{O}$ atoms for ozone generation (R11)(R13). Therefore, ozone yield by APTD increased with increasing $\mathrm{N}_{2}$ content and the minimum ozone yield by APTD was obtained at $100 \% \mathrm{O}_{2}$ content.

Additional $\mathrm{O}$ atom generation:

$$
\begin{aligned}
& \mathrm{N}_{2}(\mathrm{~A})+\mathrm{O}_{2} \rightarrow \mathrm{N}_{2}+2 \mathrm{O} \\
& \mathrm{N}_{2}(\mathrm{~B})+\mathrm{O}_{2} \rightarrow \mathrm{N}_{2}+2 \mathrm{O}
\end{aligned}
$$

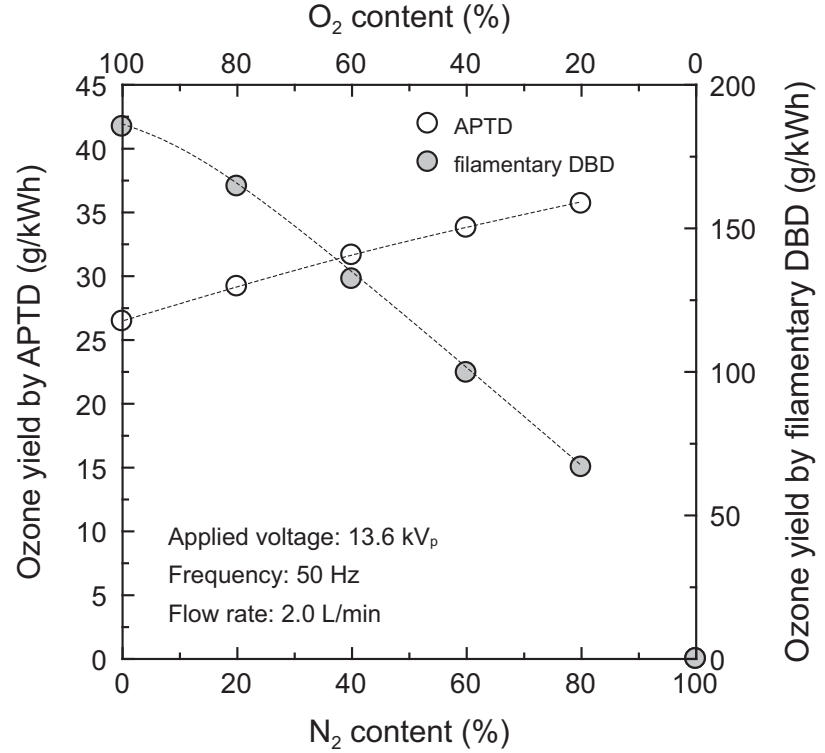

Fig. 5. Ozone yield as a function of $\mathrm{N}_{2}$ content by the two kinds of ozone generators.

Table 1. Applied voltage and frequency of this experiment.

\begin{tabular}{ccc}
\hline Discharge type & $\begin{array}{c}\text { Applied voltage } \\
(\mathrm{kVp})\end{array}$ & Frequency $(\mathrm{Hz})$ \\
\hline Filamentary DBD & 10.1 & 50 \\
APTD & 12.2 & 100 \\
\hline
\end{tabular}

Next, we calculated rate coefficients for reactions (R1), (R9) and (R10) by BOLSIG+ code $[20,21]$. In this calculation, gas temperature was set to $300 \mathrm{~K}$. From Figure $2 \mathrm{c}$ and the literature [18], values of $E / n$ were set to 144 Td for APTD and 500-800 Td for filamentary DBD. Table 2 shows the calculation results. Rate coefficient of (R1) for APTD was lower than that of filamentary DBD in the order of $10^{2}-10^{3}$. However, rate coefficients of (R9) and (R10) for APTD was smaller than filamentary DBD in the order of 10. Surprisingly, there was no significant difference between rate coefficients of (R1) and (R9), (R10) for APTD.

Table 3 shows the rate coefficients for (R11)-(R13) [22]. The rate coefficient of (R13) was higher than the other two. Therefore, (R13) is effective for the production of additional $\mathrm{O}$ atoms. 


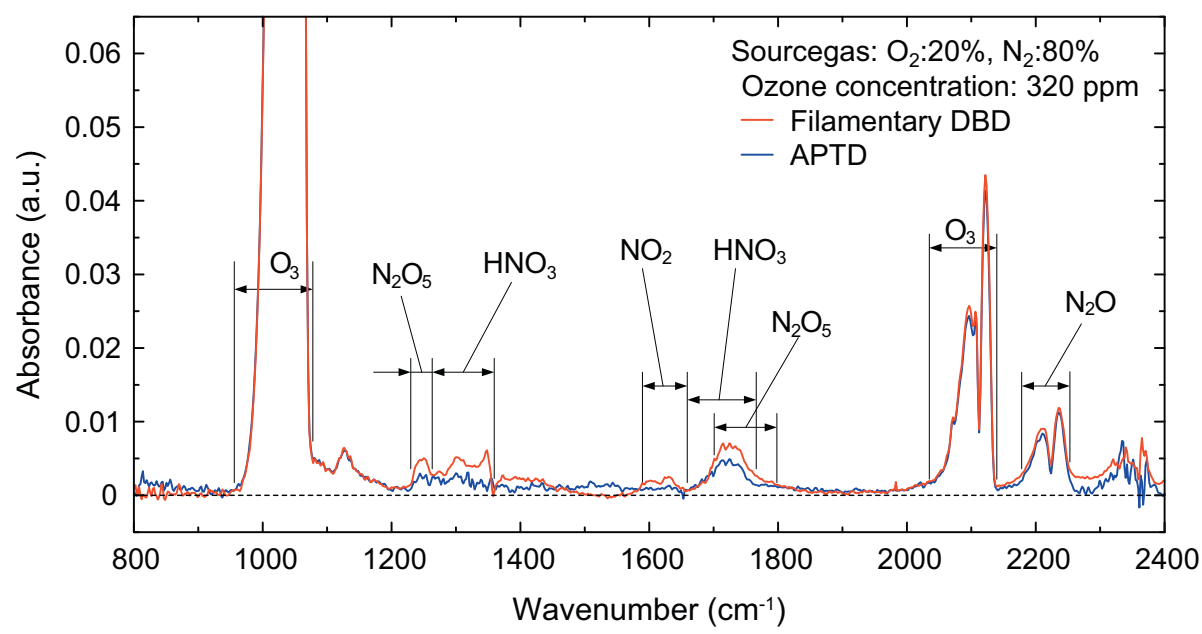

Fig. 6. Absorbance spectra of 320 ppm ozone gas generated in $80 \% \mathrm{~N}_{2}$ and $20 \% \mathrm{O}_{2}$ gas mixture.

Table 2. Rate coefficients for (R1), (R9) and (R10) in $80 \% \mathrm{~N}_{2}$ and $20 \% \mathrm{O}_{2}$ gas by BOLSIG+.

\begin{tabular}{lcc}
\hline Reaction & $\begin{array}{c}\text { APTD } \\
K\left(\mathrm{~cm}^{3} / \mathrm{s}\right)\end{array}$ & $\begin{array}{c}\text { Filamentary DBD } \\
\end{array}$ \\
& $@ 144 \mathrm{~cm} / \mathrm{s}) @ 500-800 \mathrm{Td}$ \\
\hline (R1) & $6.7 \times 10^{-11}$ & $4.4 \times 10^{-9}$ to $1.1 \times 10^{-8}$ \\
(R9) & $2.3 \times 10^{-11}$ & $1.3 \times 10^{-10}$ to $1.6 \times 10^{-10}$ \\
(R10) & $3.5 \times 10^{-10}$ & $1.6 \times 10^{-9}$ to $1.9 \times 10^{-9}$ \\
\hline
\end{tabular}

Table 3. Rate coefficients for (R11)-(R13).

\begin{tabular}{ll}
\hline Reaction & $K\left(\mathrm{~cm}^{3} / \mathrm{s}\right)$ \\
\hline R11) & $7.8 \times 10^{-14}$ \\
$(\mathrm{R} 12)$ & $2.54 \times 10^{-12}$ \\
(R13) & $3 \times 10^{-10}$ \\
\hline
\end{tabular}

These results suggest that although $\mathrm{O}_{2}$ content decreased with increasing $\mathrm{N}_{2}$ content, additional $\mathrm{O}$ atoms generated by (R11)-(R13) contribute to ozone generation in case of APTD. Actually, ozone concentration increased with increasing $\mathrm{N}_{2}$ content. In order to clarify this phenomenon in detail, further study by the numerical model of plasma chemical reaction is necessary.

\section{Conclusions}

In this paper, in order to clarify why the ozone yield by the APTD type ozone generator did not increase by using $\mathrm{O}_{2}$ as source gas, we analyzed the gas composition of the exhaust gas by FTIR spectroscopy using a gas cell, and investigated the effect of the admixture ratio of $\mathrm{N}_{2}$ and $\mathrm{O}_{2}$ in source gas to the ozone yield. The conclusions are as follows:

1. The intensities of the absorbance spectra of $\mathrm{NO}_{2}$ and $\mathrm{N}_{2} \mathrm{O}_{5}$ by the APTD are lower than those by the filamentary DBD. However, the intensities of the absorbance spectrum of $\mathrm{N}_{2} \mathrm{O}$ are almost the same for both discharges. These results suggested that $\mathrm{N}_{2}$ excitation reactions seem to be more dominant than $\mathrm{N}_{2}$ dissociation reaction in case of APTD.

2. Since excited $\mathrm{N}_{2}$ molecules can produce additional $\mathrm{O}$ atoms for ozone generation, ozone yield by APTD increased with increasing $\mathrm{N}_{2}$ content.

We would like to thank KYOCERA Corporation for providing alumina barrier electrodes. This work was supported by JSPS KAKENHI Grant Number 16K06245.

\section{References}

1. B. Eliasson, U. Kogelschatz, IEEE Trans. Plasma Sci. 19, 1063 (1991)

2. P. Olszewski, J.F. Li, D.X. Liu, J.L. Walsh, J. Hazardous Mater. 279, 60 (2014)

3. M.J. Pavlovich, H.-W. Chang, Y. Sakiyama, D.S. Clark, D.B. Graves, J. Phys. D: Appl. Phys. 46, 145202 (2013)

4. Y. Zhou, G. Huang, T. Wang, S.J. MacGregor, Q. Ren, M.P. Wilson, I.V. Timoshkin, IEEE Trans. Plasma. Sci. 44, 2129 (2016)

5. X. Zhang, B.J. Lee, H.G. Im, M.S. Cha, IEEE Trans. Plasma Sci. 44, 2288 (2016)

6. T. Shoyama, Y. Yoshioka, Electr. Eng. Jpn 161, 1 (2007)

7. N. Osawa, Y. Yoshioka, IEEE Trans. Plasma Sci. 40, 2 (2011)

8. N. Osawa, H. Kaga, Y. Fukuda, S. Harada, Y. Yoshioka, R. Hanaoka, Eur. Phys. J. Appl. Phys. 55, 13802 (2011)

9. Y. Nakai, A. Takashi, N. Osawa, Y. Yoshioka, R. Hanaoka, in Proceedings of the 20th International Symposium on Plasma Chemistry, Philadelphia, 2011

10. N. Osawa, Y. Yoshioka, J. Adv. Oxid. Technol. 17, 217 (2014)

11. N. Osawa, A. Takashi, Y. Yoshioka, R. Hanaoka, Eur. Phys. J. Appl. Phys. 61, 24317 (2013) 
12. J. Kitayama, M. Kuzumoto, J. Phys. D: Appl. Phys. 32, $3032(1999)$

13. N. Osawa, T. Tsuji, Y. Yoshioka, in Proceedings of the 15th International Symposium on High Pressure Low Temperature Plasma Chemistry, Brno, 2016

14. N. Osawa, Y. Yoshioka, R. Hanaoka, Y. Mochizuki, Y. Kobayashi, Y. Yamada, Electr. Eng. Jpn 180, 1 (2012)

15. A. Fridman, Plasma Chemistry (Cambridge University Press, 2008)

16. F. Massines, N. Gherardi, N. Naudé, P. Ségur, Eur. Phys. J. Appl. Phys. 47, 22805 (2009)

17. K.V. Kozlov, R. Brandenburg, H.-E. Wagner, A.M. Morozov, P. Michel, J. Phys. D: Appl. Phys. 38, 518 (2005)

18. U. Kogelschatz, IEEE Trans. Plasma Sci. 30, 1400 (2002)
19. M. Laroussi, K.H. Schoenbach, U. Kogelschatz, R.J. Vidmar, S. Kuo, M. Schmidt, J.J. Behnke, K. Yukimura, E. Stoffels, Non-equilibrium Air Plasmas at Atmospheric Pressure (IOP Publishing, Bristol, 2005)

20. N.A. Popov, J. Phys. D: Appl. Phys. 44, 285201 (2011)

21. G.J.M. Hagelaar, L.C. Pitchford, Plasma Source. Sci. Technol. 14, 722 (2005)

22. I.A. Kossyi, A.Y. Kostinsky, A.A. Matveyev, V.P. Silakov, Plasma Sources Sci. Technol. 1, 207 (1992)

Open Access This article is distributed under the terms of the Creative Commons Attribution License http:// creativecommons.org/licenses/by/4.0/ which permits unrestricted use, distribution, and reproduction in any medium, provided the original author(s) and source are credited. 